\title{
DISPLASIA PERKEMBANGAN PANGGUL AWAL (LAHIR HINGGA USIA 4 BULAN)
}

\author{
Vivi Sumarna \\ Engeline Angliadi
}

\author{
Program Studi Ilmu Kedokteran Fisik dan Rehabilitasi \\ Fakultas Kedokteran Universitas Sam Ratulangi Manado \\ Email: viviliu.kwok@gmail.com
}

\begin{abstract}
Developmental dysplasia of the hip refers to a continuum of abnormalities of the immature hip that can range from subtle dysplasia to dislocation. The identification of risk factors, including breech presentation and family history, should heighten a physician's suspicion of this condition. The diagnosis is based on physical examination. Palpable hip instability, unequal leg lengths, and asymmetric thigh skinfolds may be present in newborns with a hip dislocation, whereas gait abnormalities and limited hip abduction are more common in older children. The role of ultrasonography is controversial, but it is generally used to confirm the diagnosis and to assess hip development once the treatment is initiated. Bracing is the first-line treatment in children aged less than six months. Surgery is an option for children with unsuccessful non-operative treatment and in children who are diagnosed after six months of age. It is important to confirm the diagnosis of the developmental dysplasia of the hip in the early stage to improve the result of treatment and to decrease the risks of complications.
\end{abstract}

Keywords: hip, developmental dysplasia, immature, instability, bracing

\begin{abstract}
Abstrak: Displasia perkembangan panggul mengacu pada serangkaian abnormalitas pada panggul imatur yang mencakup displasia ringan hingga dislokasi. Identifikasi faktor-faktor risiko yang meliputi letak sungsang dan riwayat keluarga, harus menigkatkan kecurigaan dokter akan displasia perkembangan panggul. Diagnosis ditegakkan melalui pemeriksaan fisik. Instabilitas panggul yang dapat dipalpasi, panjang tungkai yang tidak sama, dan lipatan kulit paha yang asimetris dapat ditemukan pada bayi baru lahir dengan dislokasi panggul, sedangkan abnormalitas gait dan keterbatasan abduksi panggul lebih umum pada anak-anak yang lebih tua. Peran ultrasonografi masih kontroversial tetapi secara umum untuk mengonfirmasi diagnosis dan menilai perkembangan panggul sejak dimulainya perawatan. Penggunaan brace merupakan perawatan lini pertama pada anak-anak berusia kurang dari enam bulan. Pembedahan merupakan pilihan bagi anak-anak dengan perawatan nonoperatif yang gagal dan pada anak-anak yang didiagnosis setelah berusia enam bulan. Displasia perkembangan panggul sangat penting ditegakkan sejak dini untuk meningkatkan hasil perawatan dan mengurangi risiko komplikasi.
\end{abstract}

Kata kunci: panggul, displasia perkembangan, imatur, instabilitas, brace

Displasia perkembangan panggul (DPP) merupakan salah satu malformasi kongenital yang menjadi penyebab penting disabilitas sejak masa kanak-kanak. ${ }^{1}$ DPP mengacu pada berbagai gangguan perkembangan panggul mulai dari panggul yang agak displastik, terletak secara konsentris dan stabil, hingga yang sangat displastik dan terdislokasi. ${ }^{2}$

Penatalaksanaan DPP ditujukan pada deteksi dini, penanganan, pencegahan, dan pengenalan dini akan komplikasi. ${ }^{3}$ 
Penatalaksanaan DPP memerlukan kerjasama tim yang baik antara dokter spesialis anak, dokter spesialis bedah ortopedi, para anggota tim rehabilitasi medik, dan orang tua penderita. Tim rehabilitasi medik tersebut terdiri dari dokter spesialis kedokteran fisik dan rehabilitasi, fisioterapis, okupasi terapis, ortotis prostetiks, psikolog, petugas sosial medik, dan perawat rehabilitasi.

Algoritma penanganan saat ini tergantung baik dari tingkat keparahan abnormalitas maupun usia saat diagnosis yang meliputi: observasi, Pavlik harness, reduksi tertutup dan/atau terbuka, cetakan spica (tubuh), dan beberapa prosedur bedah lain. $^{3}$

\section{DEFINISI}

Displasia perkembangan panggul (DPP) merupakan suatu istilah komprehensif untuk menggambarkan hubungan abnormal antara kaput femoral dan asetabulum yang dapat terjadi kongenital atau dapat berkembang selama masa bayi dan/atau anak (Gambar 1)., ${ }^{3,4}$ DPP mencakup suatu spektrum luas abnormalitas panggul, mulai dari dislokasi komplit kaput femoral hingga abnormalitas asetabulum ringan atau kelemahan sendi panggul. $^{5}$

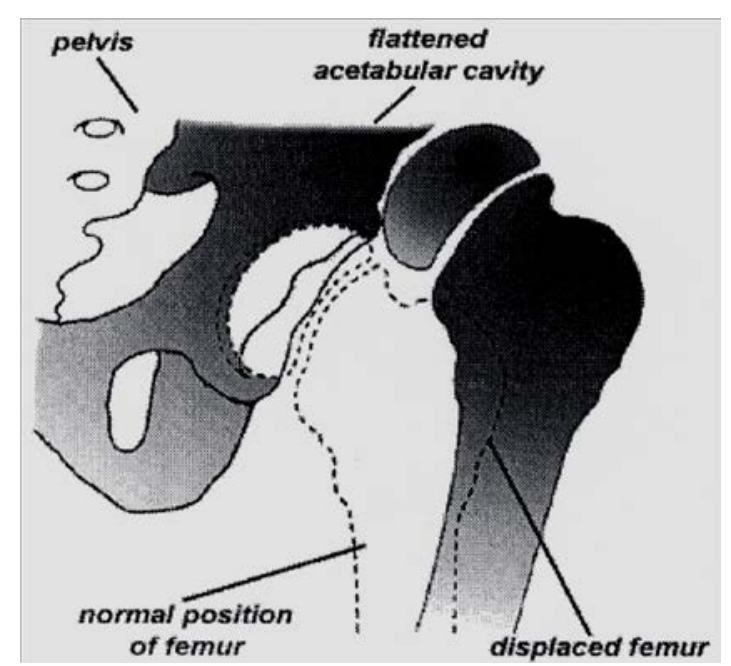

Gambar 1. Diagram yang memperlihatkan posisi femur pada panggul normal dan pada $\mathrm{DPP}^{3}$

\section{ETIOLOGI}

Risiko DPP meningkat dengan faktor terkait kendala mekanik intrauterin dan posisi abnormal pada trimester terakhir, tetapi juga dipengaruhi oleh lingkungan postnatal dan predisposisi genetik. Faktor yang terkait dengan konstriksi mekanik fetus termasuk berat badan lahir besar untuk usia kehamilan, ${ }^{6}$ letak sungsang, ${ }^{3,6,7}$ dan oligohidramnion, ${ }^{3,7}$ lebih umum ditemukan pada kasus DPP, tetapi faktor risiko perinatal yang paling penting dan berpotensi dapat dihindari ialah persalinan pervaginam dari bayi-bayi letak sungsang., ${ }^{3,6,7}$

Menghindari konstriksi mekanik postnatal telah dianjurkan untuk mencegah DPP. Praktek membedung bayi postnatal, seperti penggunaan papan buaian/ayunan pada populasi Indian Amerika dan pembedungan ketat di Jepang, dimana keduanya menyebabkan periode panjang dari ekstensi dan adduksi paha, telah dikaitkan dengan tingginya tingkat DPP yang tercatat dalam populasi tersebut. Secara teoritis, metode modern merawat bayi di negara maju, seperti melewatkan periode panjang di kursi bayi dan penggunaan popok sekali pakai yang sangat tipis yang tidak mengabduksi panggul secara luas, juga dapat memengaruhi perkembangan panggul.

Risiko keluarga untuk DPP telah dikenal baik. Dalam suatu studi, rasio kemungkinan untuk prevalensi DPP dilaporkan jauh lebih tinggi untuk ibu daripada saudara kandung, ayah, dan anakcucu, yang menunjukkan efek maternal. ${ }^{3,6,7}$ Kelemahan sendi familiar terkait hipermobilitas sendi telah diidentifikasi sebagai faktor risiko DPP, dan hipermobilitas sendi yang herediter diperkirakan $70 \%$ pada kembar dewasa perempuan. ${ }^{8}$

\section{EPIDEMIOLOGI}

Insidensi DPP bervariasi dan dipengaruhi oleh beberapa faktor seperti usia, ras, jenis kelamin, pengalaman dan pelatihan pemeriksa, dan kriteria diagnos- 
tik yang digunakan. ${ }^{3}$ Pada populasi yang tidak diskrining median prevalensi dari DPP persisten dan yang didiagnosis secara klinis diperkirakan 1,3 per $1000(0,84-1,5)$ berdasarkan studi dari 44 populasi dimana sebagian besar populasi ialah keturunan Eropa barat laut yang tinggal di Australia, Amerika Serikat, Kanada, Skandinavia, dan Inggris. $^{9}$

DPP paling sering terjadi pada anak perempuan yaitu sekitar $80 \%$. Panggul kiri terkena pada $60 \%$ anak, panggul kanan $20 \%$, dan kedua panggul 20\%. Anak pertama terkena dua kali lebih sering dari saudara kandung berikutnya. ${ }^{3,7}$ Variasi etnis dalam prevalensi dislokasi dan subluksasi pada populasi yang tidak diskrining dilaporkan lebih tinggi terutama pada populasi Jepang, Turki, Indian Amerika, dan Lapp. ${ }^{8}$ DPP jarang terjadi pada orang Negro dengan penyebab yang tidak jelas.

Terdapat peningkatan risiko DPP terkait dengan beberapa kondisi lain yang ditemukan pada posisi intrauterin abnormal dan crowding fetal. Kondisi tersebut meliputi dislokasi lutut kongenital, tortikolis muskularis kongenital, kaki metatarsus adduktus, ${ }^{3}$ dan kalkaneo-valgus. ${ }^{10}$

\section{DIAGNOSIS AWAL (LAHIR HINGGA USIA 4 BULAN)}

\section{Diagnosis klinis}

\section{Anamnesis}

Idealnya, panggul displastik terdeteksi melalui anamnesis dan pemeriksaan fisik pada hari-hari pertama kehidupan bayi. Langkah penting dalam anamnesis ialah wawancara mendalam dengan orang tua mengenai adanya riwayat DPP atau osteoartritis panggul prematur dalam keluarga, posisi intra-uteri, posisi sungsang (30\% kelahiran sungsang berkaitan dengan DPP, meskipun hal ini hanya 3\% dari semua kelahiran), jumlah kehamilan (ketidak-stabilan lebih umum terjadi pada kelahiran anak pertama), dan oligohidramnion. $^{11}$ Ketidakstabilan panggul 2-5 kali lebih dominan pada anak perempuan daripada anak laki-laki. ${ }^{12}$

\section{Pemeriksaan fisik}

Pemeriksaan fisik lengkap dari bayi baru lahir sangat penting untuk menemukan gangguan dalam sistem muskuloskeletal dan mencegah penyakit. ${ }^{12}$ Idealnya bayi harus relaks dan hangat. Seluruh pakaian, termasuk popok, harus dilepaskan dan bayi ditempatkan pada permukaan keras yang memungkinkan akses yang mudah. Pemeriksaan umum dari tulang tengkorak, trunkus, lengan, dan tungkai harus cepat dan lembut. Asimetri atau malformasi harus dicari. ${ }^{13}$

\section{Inspeksi}

Bayi baru lahir hingga berusia kurang dari tiga bulan dengan DPP dapat memiliki asimetri lipatan paha/inguinal dan lipatan poplitea akibat kemiringan panggul (Gambar 4 A, B, C). Umumnya lipatan inguinal yang normal hampir simetris dan berhenti sebelum lubang anus. Bila terjadi dislokasi posterior dan superior dari kaput femoral, lipatan inguinal asimetris, dengan lipatan kulit dari sisi yang terkena meluas ke posterior dan lateral melewati lubang anus. $^{12}$ Asimetri lipatan kulit yang jelas dapat menjadi indikasi dislokasi unilateral. ${ }^{11}$ Pada dislokasi bilateral, lipatan ini dapat simetris tetapi berakhir setelah tingkat lubang anus. Pemeriksaan terhadap asimetri lipatan kulit bukan merupakan tanda pasti dislokasi bilateral direduksi pada neonatus. ${ }^{14}$ Pemeriksaan ini sangat tidak informatif karena lipatan kulit pada neonatus hampir tidak pernah simetris. ${ }^{11}$

\section{Palpasi}

Pada masa infan awal, instabilitas merupakan tanda yang paling dapat dipercaya yang berkurang secara cepat dengan usia, $>50 \%$ dalam minggu pertama. ${ }^{15}$ Beberapa bentuk skrining klinis neonatal untuk DPP dipraktekkan di sebagian besar negara maju. Uji Ortolani dan Barlow merupakan uji klinis yang paling umum untuk mengidentifikasi ketidakstabilan panggul. $^{8}$ 


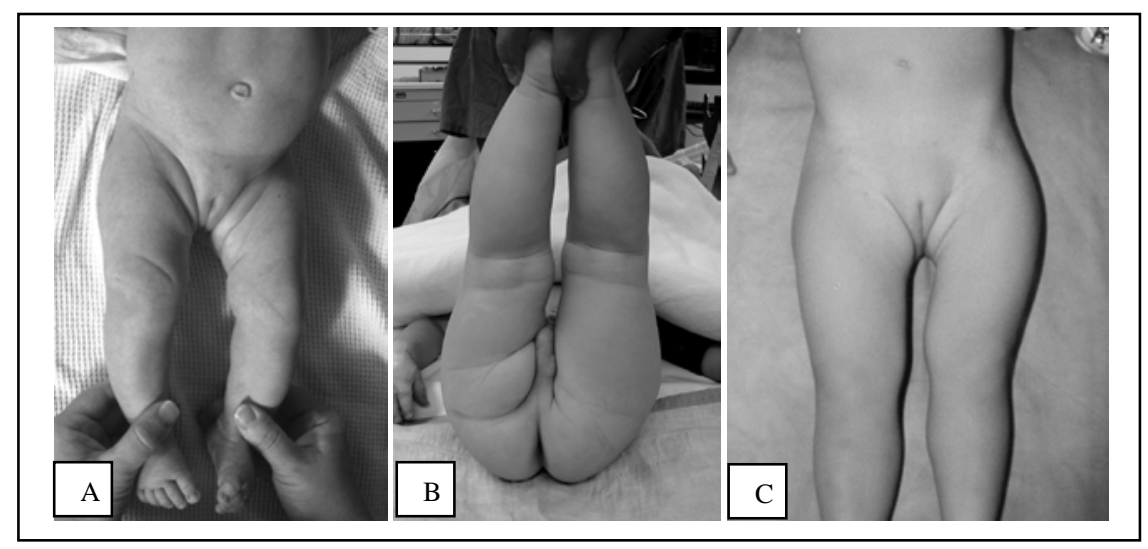

Gambar 4. A, B, Foto seorang bayi dengan asimetri lipatan kulit paha/inguinal dan lipatan poplitea yang dalam pada sisi panggul kiri yang terdislokasi. C, Foto seorang bayi dengan panggul terdislokasi bilateral. Perhatikan kontur paha yang lebar. Terdapat asimetri ringan dari lipatan kulit meskipun kedua panggul terdislokasi. ${ }^{12}$

\section{Pemeriksaan penunjang}

\section{Radiografi}

Radiografi tidak menggambarkan pelvis sejelas ultrasound pada bayi muda, yang memiliki sebagian besar panggul kartilaginosa, dan caput femoral tidak terlihat secara radiografi, tetapi lebih berguna pada masa bayi kemudian ketika ultrasound mungkin tidak dapat diandalkan. ${ }^{8,12}$

\section{Sonografi}

Sonografi telah menjadi metode yang paling umum dan bermanfaat untuk digunakan dalam analisis sendi panggul, terutama pada bayi berusia di bawah 6 bulan. Sonografi merupakan indikator yang sensitif untuk posisi, perkembangan asetabulum, dan ketidakstabilan, yang lebih akurat dibandingkan radiografi. Ultrasonografi terlalu sensitif sebagai alat skrining pada enam minggu pertama kehidupan, dan umumnya tidak boleh digunakan pada usia tersebut. ${ }^{7}$

Berbagai teknik dan kriteria telah digunakan untuk penilaian morfologi dan stabilitas panggul, salah satunya ialah metode Graf. Gambaran ultrasonografi yang diperoleh pada bidang standar digunakan untuk menentukan panggul pada salah satu dari empat kategori utama berdasarkan ciri-ciri dari asetabulum, pemodelan tulang, dan atap kartilago. Penampilan morfologik tersebut mewakili suatu rangkaian kesatuan dari normal hingga displasia berat, dan bukan empat kelompok tersendiri. ${ }^{8}$ Selanjutnya, indikasi atau ambang untuk penanganan tetap kontroversial: beberapa peneliti memantau anak-anak dengan panggul tipe $2 \mathrm{a}$ dan merawat mereka dengan panggul $2 \mathrm{c}$ atau $2 \mathrm{~d}$, sementara yang lain mengikuti kasus panggul tipe 2c dan 2d dan merawat tipe 3 dan 4. Meskipun keterbatasan ini, metode Graf telah memperoleh penerimaan di sebagian besar Eropa, meskipun dengan modifikasi. $^{16}$

\section{PENANGANAN}

Banyak acuan pustaka setuju bahwa tujuan utama penanganan DPP ialah meningkatkan relokasi panggul nontraumatik pada usia semuda mungkin sehingga tercipta hubungan konsentris antara caput femoral dan acetabulum, dan untuk mempertahankan reduksi dan stabilitas dalam posisi aman sehingga sendi panggul dapat melanjutkan perkembangan normal, sehingga meningkatkan kemungkinan dari keluaran yang baik secara fungsional dan anatomis. ${ }^{8,12}$ Penghindaran pembedahan melalui deteksi dini dan manajemen non-bedah merupakan tujuan sekunder yang penting, paling tidak karena pembedahan dikaitkan dengan 
risiko besar nekrosis avaskular. Penanganan non-bedah mempertahankan panggul dalam posisi fleksi dan abduksi menggunakan splint. Splint berbeda dalam ukuran, bentuk, kemudahan dalam menggunakan dan melepaskan dan masalah pada mobilitas. $^{8}$

\section{Penanganan awal (lahir hingga usia 4 bulan)}

Indikasi penanganan mencakup semua panggul terdislokasi dan tersubluksasi secara khas dan semua panggul tidak stabil atau displastik secara persisten. Panggul dengan Barlow positif saat lahir sering menjadi stabil dalam 3 minggu pertama. Untuk alasan ini, biasanya tidak dirawat panggul dengan Barlow positif dalam 3 minggu pertama; namun, panggul ini perlu evaluasi menyeluruh untuk menjamin perkembangan panggul normal. Juga direkomendasikan evaluasi tindak lanjut mencakup sonografi dan penanganan pada panggul dengan ketidakstabilan persisten pada usia 3 minggu. Panggul tidak stabil/displastik secara persisten sangat sulit untuk didiagnosis melalui peme- riksaan fisik. Acuan pustaka menyatakan bahwa anak-anak dengan faktor risiko tinggi layak mendapat evaluasi sonografi. Beberapa komunitas melakukan skrining panggul dengan sonografi untuk mendeteksi panggul displastik atau imatur. Panggul imatur yang berkembang menjadi normal tidak memerlukan penanganan. Panggul displastik persistenlah yang layak menerima penanganan. Acuan pustaka merekomendasikan penanganan panggul yang tetap displastik setelah 3 sampai 6 minggu. $^{12}$

Ketika diagnosis dibuat pada masa bayi awal dan perubahan patologis sekunder belum berkembang, panggul terdislokasi sering dapat direduksi dengan manuver lembut tanpa perlu menggunakan traksi atau anestesi. Penanganan tersebut berdasarkan pada konsep bahwa memposisikan panggul tereduksi pada fleksi dan abduksi ringan akan merangsang perkembangan sendi yang normal. Pemeliharaan reduksi merupakan masalah penting dalam penanganan. Pavlik harness merupakan penanganan orthosis yang paling banyak digunakan saat ini (Gambar 2).

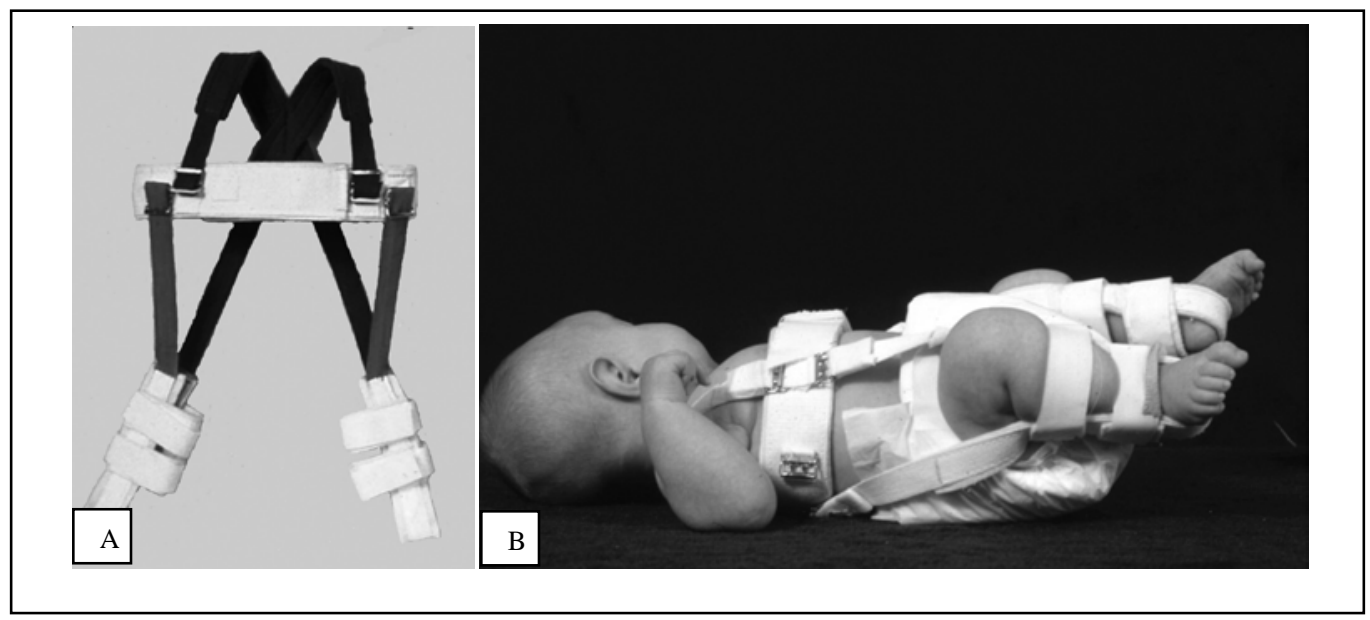

Gambar 2. A, Pavlik harness. B, Foto seorang bayi dengan Pavlik harness ${ }^{8}$

Terdapat sejumlah orthotik lain yang tersedia yang telah dikembangkan untuk mempertahankan panggul dalam fleksi dan abduksi, termasuk splint Von Rosen, bantal abduksi, splint Derqui, bantal Frejka, splint Petit, dan splint Craig atau Infeld.
Perangkat ini perlu sering dikaji ulang, menuntut pengetahuan orang tua tentang cara menempatkannya kembali dalam posisi yang benar setelah mengganti popok. Mereka sering terlalu lunak atau terlalu kaku, memungkinkan gerakan bebas 
panggul atau memaksa panggul ke abduksi hebat, yang menyebabkan masalah seperti redislokasi atau nekrosis avaskular dari kaput femoral. ${ }^{12}$

\section{SIMPULAN}

Displasia Perkembangan Panggul telah menggantikan istilah yang lebih tradisional yaitu "dislokasi panggul kongenital". DPP mengacu pada serangkaian abnormalitas pada panggul imatur yang mencakup displasia ringan hingga dislokasi caput femoral dari acetabulum.

Identifikasi faktor-faktor risiko meliputi berat lahir besar untuk usia kehamilan; oligohidramnion; presentasi sungsang; persalinan pervaginam dari bayibayi letak sungsang; pembedungan bayi post natal; papan buaian Indian Amerika; faktor risiko keluarga; jenis kelamin perempuan; etnis Jepang, Turki, Indian Amerika, dan Lapp.

Mendiagnosis DPP dapat menjadi suatu tantangan. Pencegahan dari deteksi yang terlambat merupakan tujuan bagi semua praktisi. Berbagai studi menunjukkan bahwa penggunaan teknik diagnostik saat ini dapat meminimalkan jumlah keterlambatan diagnosis tetapi tidak mengeliminasinya. Para praktisi harus meningkatkan keterampilan dan pengalaman dalam melakukan pemeriksaan, dan harus mempertahankan keahlian sepanjang karirnya.

Algoritma penanganan saat ini tergantung baik dari tingkat keparahan abnormalitas maupun usia saat diagnosis. Penanganan tersebut meliputi observasi, Palvik harness, reduksi tertutup dan/atau terbuka, cetakan spica (tubuh) dan beberapa prosedur bedah lain. ${ }^{3}$

\section{DAFTAR PUSTAKA}

1. Furnes O, Lie SA, Espehaug B, Vollset SE, Engesaeter LB, Havelin LI. Hip disease and the prognosis of total hip replacements. A review of 53,698 primary total hip replacements reported to the Norwegian Arthroplasty Register
1987-99. J Bone Joint Surg Br. 2000;83:579-86.

2. Murray KA, Crim JR. Radiographic imaging for treatment and follow-up of developmental dysplasia of the hip. Semin Ultrasound CT MR. 2001;22: 306-40.

3. Hart ES, Albright MB, Rebello GN, Grottkau BE. Developmental dysplasia of the hip. Nursing implications and anticipatory guidance for parents. Orthopaedic Nursing. 2006;25:2.

4. Weinstein SL. Developmental hip dysplasia and dislocation. In: Morrissy RT, Weinstein SL, editors. Lovell and Winter's pediatric orthopaedics. Philadelphia: Lippincott Williams and Wilkins, 2001; p. 905-56.

5. Herring JA. Developmental dysplasia of the hip. In: Herring JA, editor. Tachdjian's Pediatric Orthopaedics. Philadelphia: WB Saunders Co, 2002; p. 513-646.

6. Gelfer P, Kennedy KA. Developmental dysplasia of the hip practice guidelines. Journal of Pediatric Health Care. 2008;22:318-22.

7. Storer SK, Skaggs DL. Developmental dysplasia of the hip. American Academy of Family Physicians. 2006; 74:1310-6.

8. Dezateux C, Rosendahl K. Seminar for Developmental Dysplasia of the Hip. Lancet. 2007;369:1541-52.

9. Brown J, Dezateux C, Karnon J, Parnaby A, Arthur R. Efficiency of alternative policy options for screening for developmental dysplasia of the hip in the United Kingdom. Arch Dis Child. 2003;88:760-6.

10. Patel H. Preventive health care, 2001 update: screening and management of developmental dysplasia of the hip in newborns. Can Med Assoc J. 2001; 164:1669-77.

11. Hefti F. Pediatric Orthopedics in Practice. Berlin Heidelberg: Springer-Verlag, 2007.

12. Bowen JR, Kotzias-Neto A. Developmental dysplasia of the hip. Brooklandville, Maryland: Data Trace Publishing Company, 2006: p. 53-9.

13. Benson M, Fixsen J, Macnicol M, Parsch K. Children's Orthopaedics and Fractures (3rd ed). London: SpringerVerlag, 2010. 
14. Jari S, Paton RW, Srinivasan MS. Unilateral limitation of abduction of the hip. A valuable clinical sign for DDH? J Bone Joint Surg Br. 2002;84:104-7.

15. Alexander MA, Matthews DJ. Pediatric rehabilitation: principles and practice (4th ed). New York: Demos Medical
Publishing, 2010.

16. Von Kries R, Ihme N, Oberle D, Stark R, Altenhofen L, Niethard FU. Effect of ultrasound screening on the rate of first operative procedures for developmental hip dysplasia in Germany. Lancet. 2003;362:1883-7. 